\title{
A Clinical Study on Traumatic Pericarditis and Traumatic Reticuloperitonitis in Twelve Holstein Friesian Cattle
}

\begin{abstract}
Background: Traumatic injury caused by swallowed -sharp foreign object is one of the common conditions in dairy animal resulting into development of traumatic pericarditis (TP) and traumatic reticuloperitonitis (TRP). Under field conditions both conditions mimic the same clinical signs making it difficult to differentiate as well as render to choose ideal therapeutic management. The present study was aimed to evaluate clinical, hematobiochemical and ultrasonographic changes in cattle to clinically differentiate between TP and TRP cases.

Methods: From the period of January 2020 to December 2020, total twelve Holstein Friesian cattle were investigated for TP and TRP. In the present study, six animals each suffering from TP and TRP were included along with six normal healthy animals as control. Different clinical signs, haemato-biochemical parameters and ultrasonographical findings were recorded in each group and comparative analysis was done.

Result: Brisket edema, bilateral jugular vein engorgement and arched back conditions were most reported clinical signs in both the groups. Significant changes were recorded in the values of red blood cells, lymphocyte, blood urea nitrogen, creatinine and SGOT between both the groups. Significant drop in hemoglobin level was observed in TP affected group. No significant changes were observed in white blood cells, packed cell volume, monocyte counts and eosinophil counts. Significant increase in fibrinogen concentration recorded in both the groups. In ultrasonography, accumulation of anechoic fluid around heart in TP and reticular wall thickening in TRP was most consistent findings.

Key words: Holstein friesian, Traumatic pericarditis, Traumatic reticuloperitonitis.
\end{abstract}

\section{INTRODUCTION}

Ingestion of sharp object is one of the most common cause of traumatic reticuloperitonitis (TRP) and traumatic pericarditis (TP) in cattle and buffalo (Rajput et al., 2018). TRP and TP are sporadic conditions in Holstein Friesian cattle caused by perforation of the reticulum by any incisive sharp material. It is a quotidian cause of abdominal surgery in cattle (Mohamed, 2010). Cattle are more susceptible to foreign body syndrome than small ruminants because they do not use their lips for prehension and are likely to choose chopped feed (Braun, 2003). Grain ration feeding is one of the important source of sharp object ingestion. Honeycomb like structure of reticulum helps foreign body to fix in and reticular contraction facilitates foreign body to get through the wall and further pericarditis occurs. It is most common pericardial disorder in cattle (Bexiga et al., 2008). Respiratory distress is one of the common finding in both the conditions. Death after foreign body penetration of pericardium is usually caused by progressive fibrosive constrictive pericarditis and epicarditis (Buczinski et al., 2010), cardiac tamponade from perfora of the coronary artery has also been found (Awadhiya et al., 1974). The present study performed to compare the TRP with its most common complication TP based on clinical examination, hematobiochemical analysis and ultrasonographic evaluation.

\section{MATERIALS AND METHODS}

The work was carried out during the period from January,
Department of Medicine, College of Veterinary Science and Animal Husbandry, Kamdhenu University, Sardarkrushinagar-385 506, Gujarat, India.

Corresponding Author: A.S. Prajapati, Department of Medicine, College of Veterinary Science and Animal Husbandry, Kamdhenu University, Sardarkrushinagar-385 506, Gujarat, India.

Email: ankitprjpt1@gmail.com

How to cite this article: Prajapati, A.S., Suthar, A.N., Chauhan, P.M., Patel, K.D., Patel, R.M., Patel, A.M. (2021). A Clinical Study on Traumatic Pericarditis and Traumatic Reticuloperitonitis in Twelve Holstein Friesian Cattle. Indian Journal of Animal Research. DOI: 10.18805/IJAR.B-4566.

Submitted: 09-06-2021 Accepted: 08-12-2021 Online: 01-01-2022

2020 to Decemebr, 2020 at Veterinary Clinical Complex, College of Veterinary Science and Animal Husbandry, Kamdhenu University, Sardarkrushinagar. Total twelve animals aged between 3 to 10 years were tentatively evaluated for TP (Group II) and TRP (Group III). Control group (Group I) comprised of six normal healthy cattle. Clinical examination were recorded for each animal. Details are tabulated in Table 1. Two ml blood was collected in EDTA vials from jugular vein and subjected to evaluate hematological values like PCV\%, hemoglobin, differential leukocytes (WBC) and total erythrocytic count (RBC). Five $\mathrm{ml}$ blood was collected from same site in clot activator vial for biochemical analysis. Plasma was separated from blood 
and fibrinogen was evaluated in each group by using semiautomatic coagulometer. Ultrasonographic examination of all cattle was performed to evaluate the internal condition. The area over the reticulum and the left and right sides of thethoracic cavity up to the elbow joints were clipped. Gel was applied to facilitate better examination and the $2-5 \mathrm{MHz}$ convex probe was used. Pericardiocentesis was performed in TP cases to relieve pain and same was examined for bacterial culture. The results data were analyzed by using one way ANNOVA in GraphPad Prism 8.0.1 and presented as mean \pm standard error of mean as given in Table 2 .

\section{RESULTS AND DISCUSSION}

Cattles with traumatic reticulo-peritonitis (TRP) and traumatic pericarditis (TP) exhibited different clinical signs. Brisket edema and bilateral engorgement of jugular vein were the most reported clinical signs in TP and elucidation of pain at xiphoid region in TRP (Fig 1 and 2). Similar clinical signs were also reported previously (Roth and King, 1991; Radostitis, 2007; Braun, 2008; Hajighahramani et al., 2010; Reddy et al., 2014; Suthar et al., 2017). Significant increase in granulocyte and SGOT (AST) value observed in TP and TRP groups as compared to control (Fig 12). Significant increase in blood urea nitrogen (BUN) and creatinine was observed only in TP group as compare to the control group. Significant reduction in red blood cell (RBC) and lymphocyte count was observed in TRP and TP groups and significant decline in hemoglobin was observed in only TP group. Decline in RBC and hemoglobin values might be due to possible organ damage and internal hemorrhage (Fig 10 and 11). No significant changes were observed in white blood cell (WBC), packed cell volume (PCV), monocyte count,

Table 1: Clinical findings in different groups of cattle.

\begin{tabular}{|c|c|c|c|c|c|c|c|}
\hline \multirow{2}{*}{$\begin{array}{l}\text { Parameters } \\
\text { Age (Year) }\end{array}$} & \multirow{2}{*}{$\frac{\text { Group }}{A}$} & \multicolumn{6}{|c|}{ Animal } \\
\hline & & 6 & 7 & 7.5 & 9 & 9 & 6.6 \\
\hline & $\mathrm{B}$ & 7 & 9 & 6 & 8 & 7.5 & 10 \\
\hline & C & 6 & 7 & 5.5 & 8.5 & 7 & 9 \\
\hline \multirow[t]{3}{*}{ Temperature $\left({ }^{\circ} \mathrm{F}\right)$} & A & 100.4 & 99.9 & 101.3 & 100.9 & 101.7 & 102 \\
\hline & B & 103 & 102.2 & 99 & 101 & 100.2 & 99.7 \\
\hline & $\mathrm{C}$ & 101.6 & 102.2 & 103 & 103.6 & 102.5 & 101.3 \\
\hline \multirow[t]{3}{*}{ Heart rate (per minute) } & $A$ & 62 & 68 & 70 & 72 & 65 & 66 \\
\hline & B & 87 & 91 & 84 & 92 & 83 & 77 \\
\hline & $\mathrm{C}$ & 65 & 72 & 84 & 76 & 84 & 86 \\
\hline \multirow[t]{3}{*}{ Respiratory rate (per minute) } & $A$ & 40 & 38 & 41 & 45 & 35 & 49 \\
\hline & B & 48 & 51 & 70 & 72 & 64 & 75 \\
\hline & C & 39 & 52 & 52 & 67 & 56 & 58 \\
\hline \multirow[t]{3}{*}{ Mucus membrane } & $A$ & Normal & Normal & Normal & Normal & Normal & Normal \\
\hline & B & Pale & Pale & Pale & Pale & Normal & Pale \\
\hline & C & Normal & Congested & Congested & Congested & Congested & Pale \\
\hline \multirow[t]{3}{*}{ Lymphnode } & A & Normal & Normal & Normal & Normal & Normal & Normal \\
\hline & B & Normal & Normal & Normal & Normal & Normal & Normal \\
\hline & C & Normal & Normal & Normal & Normal & Normal & Normal \\
\hline \multirow[t]{3}{*}{ Pain test } & A & Negative & Negative & Negative & Negative & Negative & Negative \\
\hline & B & Positive & Negative & Negative & Positive & Negative & Negative \\
\hline & $\mathrm{C}$ & Positive & Positive & Positive & Negative & Positive & Positive \\
\hline \multirow[t]{3}{*}{ Heart sound } & $A$ & Normal & Normal & Normal & Normal & Normal & Normal \\
\hline & B & Normal & Muffled & Normal & Muffled & Muffled & Muffled \\
\hline & C & Normal & Normal & Tachycardia & Normal & Tachycardia & Tachycardia \\
\hline \multirow[t]{4}{*}{ Jugular vein } & $A$ & Normal & Normal & Normal & Normal & Normal & Normal \\
\hline & B & Bilateral & Bilateral & Bilateral & Bilateral & Bilateral & Bilateral \\
\hline & & Distension & Distension & Distension & Distension & Distension & Distension \\
\hline & C & Normal & Normal & Normal & Normal & Normal & Normal \\
\hline \multirow[t]{3}{*}{ Brisket edema } & A & Absent & Absent & Absent & Absent & Absent & Absent \\
\hline & $\mathrm{B}$ & Present & Present & Present & Present & Present & Present \\
\hline & C & Absent & Absent & Absent & Absent & Absent & Absent \\
\hline \multirow[t]{3}{*}{ Ferroscopy } & A & Negative & Negative & Negative & Negative & Negative & Negative \\
\hline & B & Negative & Negative & Negative & Positive & Negative & Negative \\
\hline & C & Positive & Positive & Positive & Negative & Negative & Positive \\
\hline
\end{tabular}

Group A= Control; Group B= TP; Group C= TRP. 
A Clinical Study on Traumatic Pericarditis and Traumatic Reticuloperitonitis in Twelve Holstein Friesian Cattle

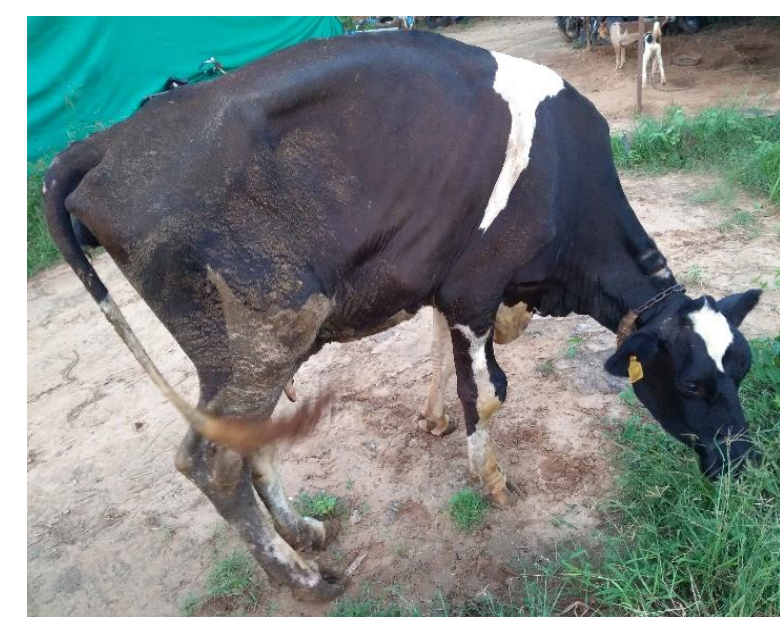

Fig 1: Arch back condition in cattle.

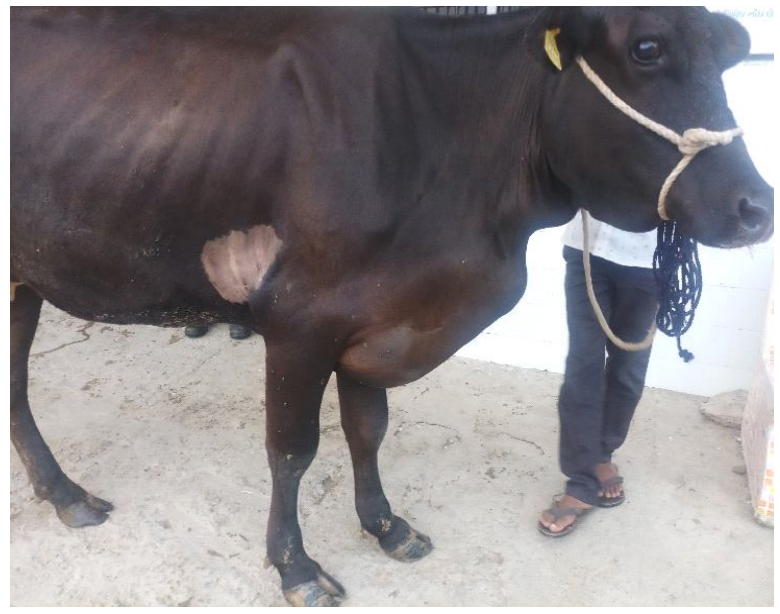

Fig 2: Brisket edema in cattle. eosinophil count and albumin in any groups. Similar values were reported by Saleh et al. (2008). Rise in BUN and creatinine levels may be due to renal impairment and dehydration resulting into azotemia (Mohamed, 2010). Similar results were reported by Sasikala et al., 2018. In our study, fibrinogen concentration was significantly elevated in TRP and TP group indicating greater inflammatory changes as compared to healthy animals (Fig 13). Fibrinogen is an acute-phase protein and may be increased as early as 2 to 3 days after the onset of illness (Francoz and Guard, 2015). Fibrinogen is often increased in the absence of changes in leukocyte numbers and therefore is a better indicator for inflammation. Therefore, fibrinogen estimation is one of the most important tool to identify the magnitude of inflammation and period of illness in dairy animals. In clinical condition TP and TRP are associated with presence of foreign body which is confirmed by standard radiographic technique (Fig 4 ).

\section{Ultrasonography}

Ultrasonography is an integral part of bovine medicine as an important diagnostic tool. Abnormal ultrasonographic changes helps in diagnosis of conditions like TP and TRP. In traumatic pericarditis accumulation of fluid along with fibrin strands was noticed around the pericardium in our study (Fig 3). Fibrin deposits can be evaluated to determine the severity of the traumatic pericarditis (Fig 5 and 6). There was increase in the distance between pericardium and epicardium due to accumulation of hypoechoic effusion (Fig 7, 8 and 9). Ultrasonography of the abdomen revealed hyperechoic reticulum, adhesion with abdominal wall and diminished or no reticular movement. Similar finding were reported by Ibrahim and Gomma (2016), Mohamed (2010) and Flock (2004).

Table 2: Values of different hemato-biochemcial parameters in different groups.

\begin{tabular}{|c|c|c|c|}
\hline \multirow[t]{2}{*}{ Parameters } & \multicolumn{3}{|c|}{$(\mathrm{n})$} \\
\hline & Control $(n=6)$ & $\operatorname{TP}(n=6)$ & $\operatorname{TRP}(n=6)$ \\
\hline WBC $\left(10^{3} / \mu L\right)$ & $8.05 \pm 0.97$ & $10.12 \pm 1.61$ & $12.47 \pm 0.94$ \\
\hline $\operatorname{RBC}\left(10^{6} / \mu \mathrm{L}\right)$ & $6.22 \pm 0.34$ & $4.82 \pm 0.58^{*}$ & $5.02 \pm 0.34^{*}$ \\
\hline Hemoglobin (gm/dl) & $9.23 \pm 0.39$ & $7.30 \pm 0.33^{*}$ & $7.88 \pm 0.57$ \\
\hline HCT (\%) & $24.07 \pm 0.59$ & $21.18 \pm 1.01$ & $23.00 \pm 1.47$ \\
\hline LY (\%) & $50.48 \pm 3.62$ & $33.27 \pm 5.22^{*}$ & $32.52 \pm 4.02^{*}$ \\
\hline $\mathrm{MO}(\%)$ & $1.72 \pm 1.26$ & $0.75 \pm .032$ & $0.40 \pm 0.27$ \\
\hline EO $(\%)$ & $4.75 \pm 0.72$ & $4.92 \pm 1.40$ & $2.28 \pm 0.80$ \\
\hline GR $(\%)$ & $31.38 \pm 1.63$ & $61.00 \pm 6.46^{* *}$ & $61.58 \pm 6.57^{* *}$ \\
\hline SGOT (IU/L) & $40.85 \pm 3.09$ & $83.70 \pm 7.43^{* *}$ & $99.13 \pm 9.52^{* *}$ \\
\hline Albumin (g/dl) & $3.39 \pm 0.34$ & $2.43 \pm 0.31$ & $3.50 \pm 0.21$ \\
\hline $\mathrm{TP}(\mathrm{g} / \mathrm{dl})$ & $6.05 \pm 0.72$ & $8.70 \pm 1.02^{*}$ & $8.01 \pm 0.33$ \\
\hline BUN (mg/dl) & $3.97 \pm 0.38$ & $33.330 \pm 10.36^{*}$ & $17.67 \pm 3.97$ \\
\hline Creatinine $(\mathrm{mg} / \mathrm{dl})$ & $0.76 \pm 0.10$ & $2.50 \pm 0.70^{*}$ & $1.25 \pm 0.31$ \\
\hline Fibrinogen (mg/dl) & $306.50 \pm 7.31$ & $630.83 \pm 7.78^{* \star}$ & $463.17 \pm 9.02^{* *}$ \\
\hline
\end{tabular}

Significance * $\mathrm{P}<0.05 ;{ }^{* *} \mathrm{P}<0.01$. 
A Clinical Study on Traumatic Pericarditis and Traumatic Reticuloperitonitis in Twelve Holstein Friesian Cattle

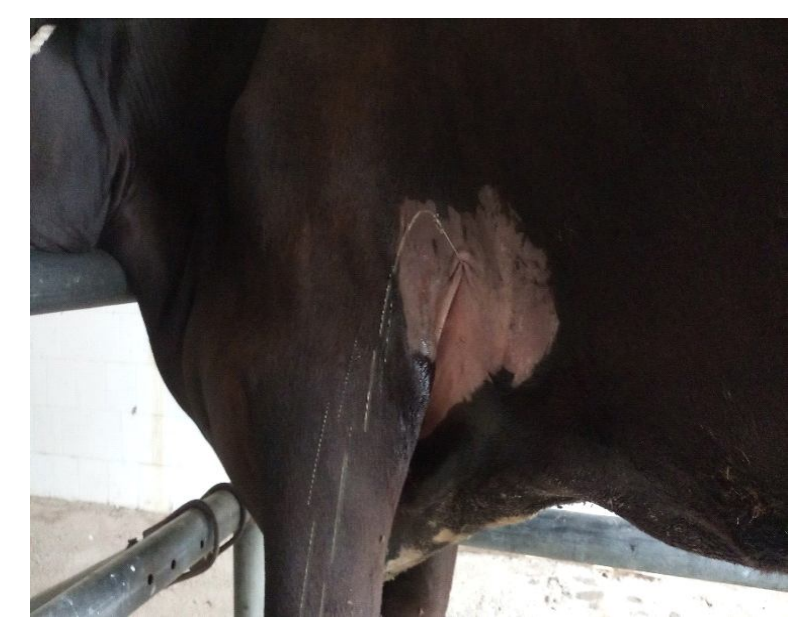

Fig 3: Pericardiocentesis in cattle having TP.

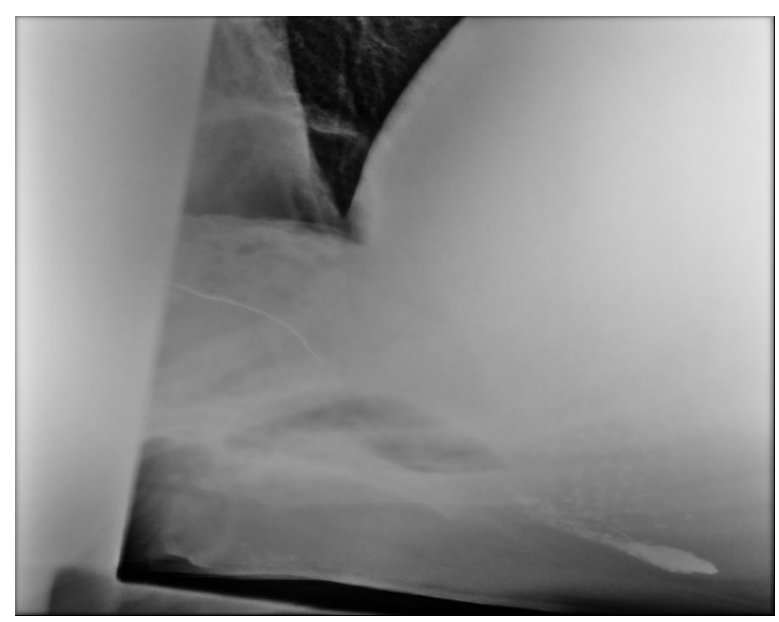

Fig 4: Radiographic examination in cattle displaying foreign body.

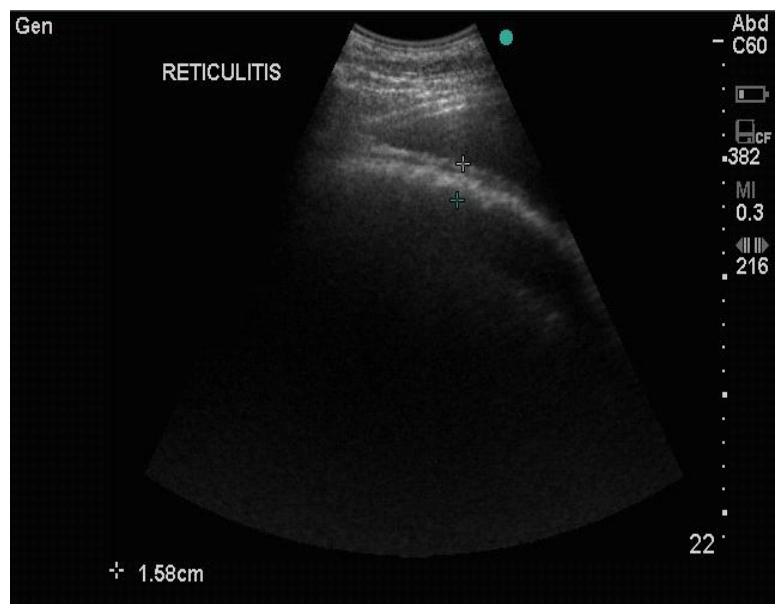

Fig 5: Reticulum with hyperechoec border in cattle with TRP.

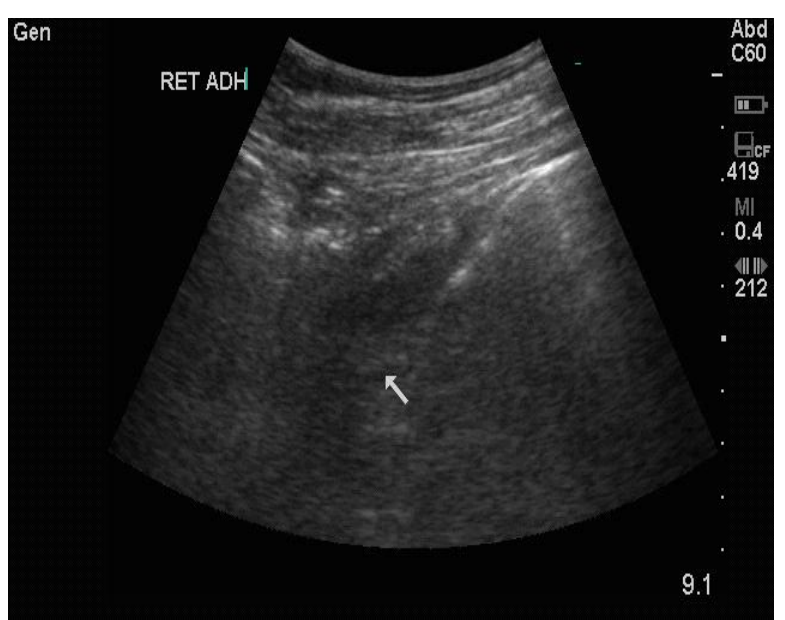

Fig 6: Reticular adhesion with abdominal wall in cattle with TRP.

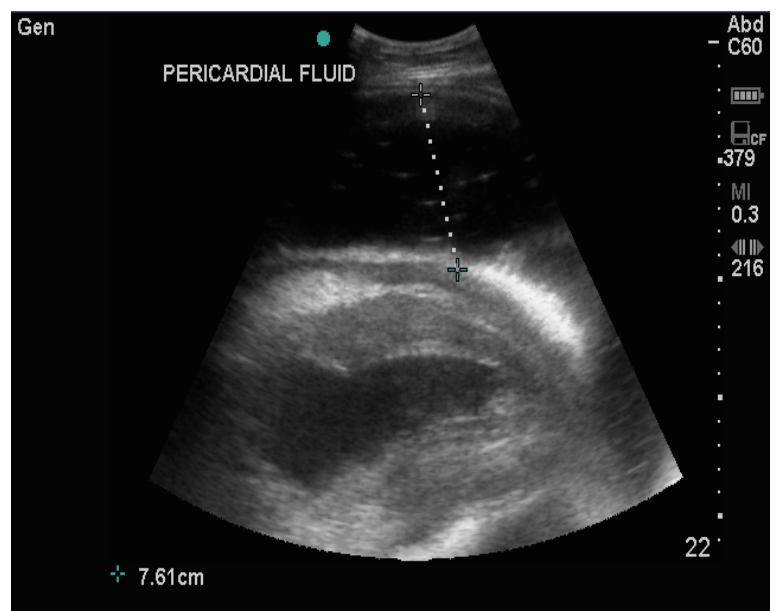

Fig 7: Presence of anechoic fluid around the heart in TP.

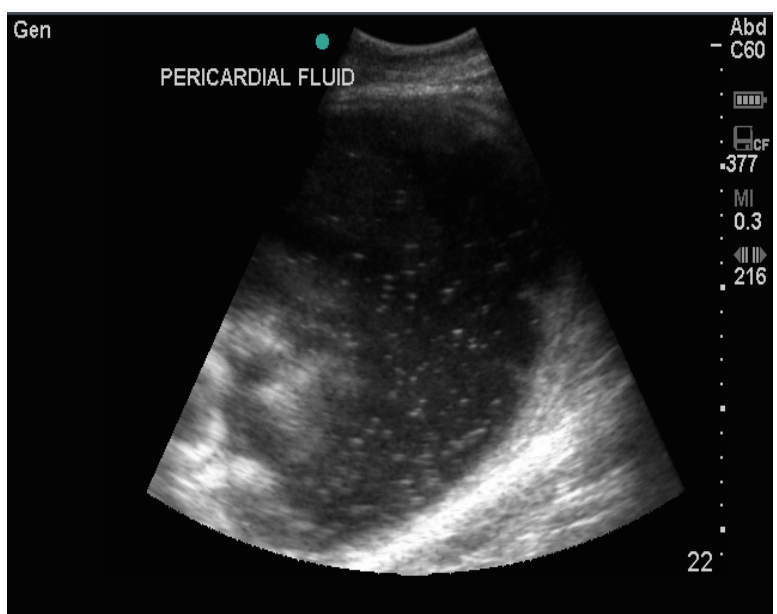

Fig 8: Hyperechoic dots indicates presence of fibrinous and purulent exudate. 
A Clinical Study on Traumatic Pericarditis and Traumatic Reticuloperitonitis in Twelve Holstein Friesian Cattle

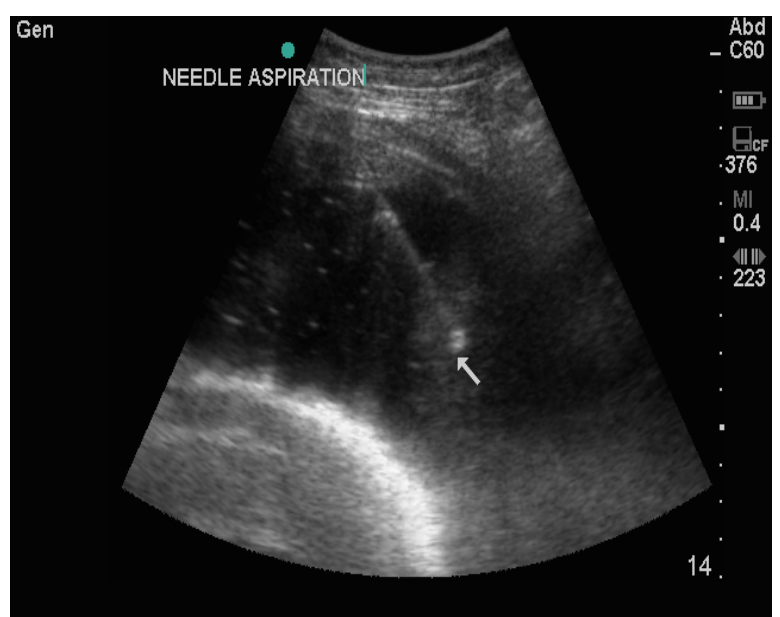

Fig 9: Ultrasonography guided pericardiocentesis of accumulated fluid.

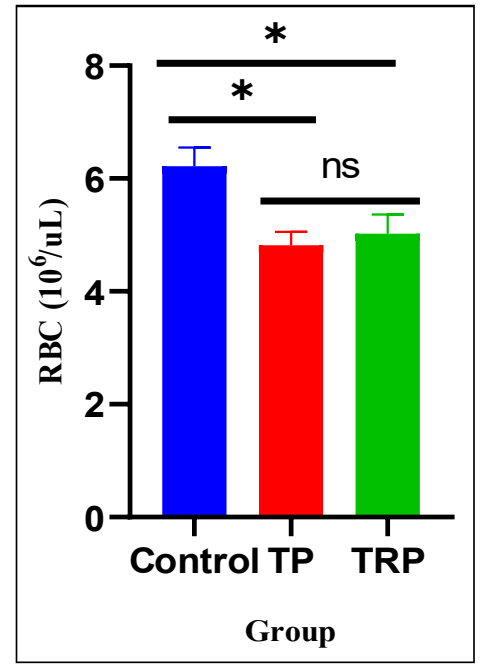

Fig 10: Significant decrease in RBC count in TP and TRP group as compare to control group.

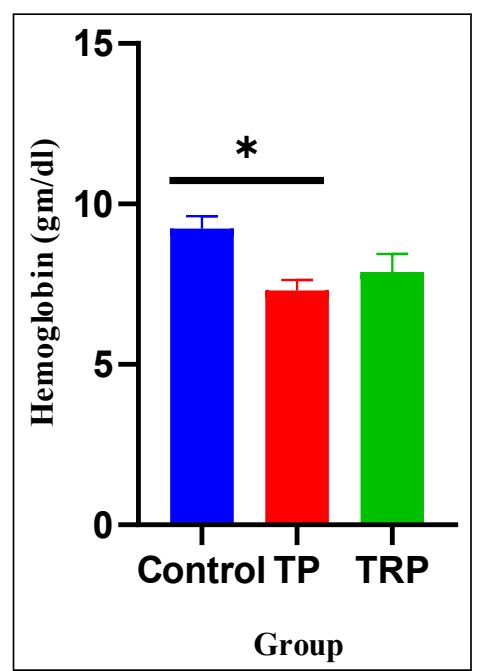

Fig 11: Significant decrease in hemoglobin value in TP group as compare to control group.

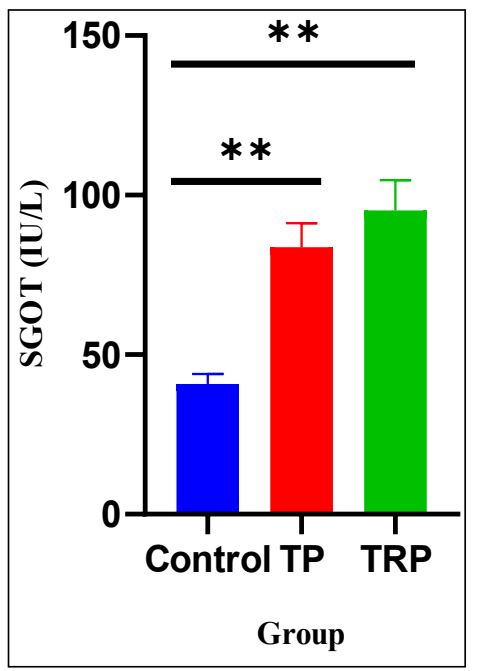

Fig 12: Significant increase in SGOT count in TP and TRP group as compare to control group.

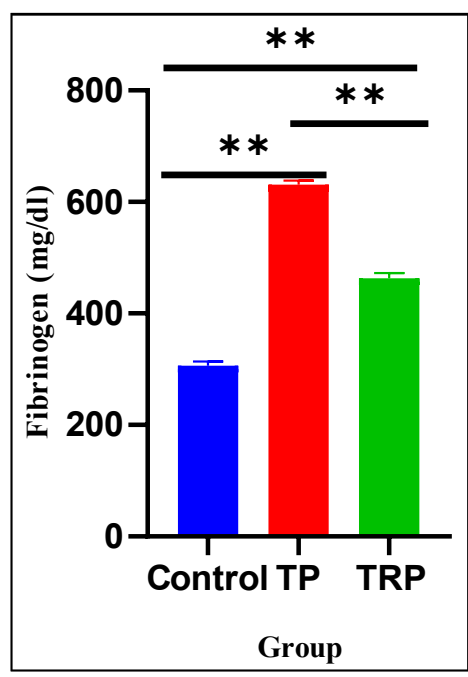

Fig 13: Significant alteration in fibrinogen concentration.

\section{CONCLUSION}

TRP and TP are one of the challenging conditions in large animal practices. Brisket edema, bilateral jugular vein engorgement, arch back condition and pain at xiphoid region are the most reported sign TP and TRP. The leukogram and fibrinogen concentration are an aid in diagnosis of TP and TRP in cattle. Accumulation of fluid around heart in TP, thickening of reticular wall and adhesion of reticulum with abdominal wall in TRP are the most reported ultrasonogaphic findings. Prevention of such conditions can be done passing feed over magnet to check the ingestion of foreign material.

\section{ACKNOWLEDGEMENT}

The authors acknowledges the Principal for providing necessary facility to carried out above work as well as Department of Gynecology and Obstetrics, Department of Clinics, Department of Surgery and Radiology for their support. 
A Clinical Study on Traumatic Pericarditis and Traumatic Reticuloperitonitis in Twelve Holstein Friesian Cattle

\section{REFERENCES}

Awadhiya, R.P., Kolte, G.N., Vegad, J.L. (1974). Cardiac tamponade: A fatal complication of traumatic reticulitisin cattle. Veterinary Record. 95: 260-262.

Bexiga, R., Mateus, A., Philbey, A.W., Ellis, K., Barrett, D.C., Mellor, D.J. (2008). Clinicopathological presentation of cardiac disease in cattle and its impacton decision making. Veterinary Record. 162: 575-80.

Braun, U. (2003). Ultrasonography in gastrointestinal diseases in cattle. Veterinary Journal. 166: 112-124.

Braun, U. (2008). Traumatic pericarditis in cattle: Clinical, radiographic and ultrasonographic findings. Veterinary Journal. 182(2): 176-186.

Buczinski, S., Rezakhani, A., Boerboom, D. (2010). Heart disease in cattle: Diagnosis therapeutic approaches and prognosis. Veterinary Journal. 184(3): 258-263.

Flock, M. (2004). Diagnostic ultrasonography in cattle with thoracic disease. Veterinary Journal. 167(3): 272-280.

Francoz, D. and Guard, C.L. (2015). Traumatic reticuloperitonitis (hardware disease, traumatic reticulitis) Large Animal Internal Medicine. St. Louis: Elsevier Mosby; 805-807.

Hajighahramani, S. and Ghane, M. (2010). Traumatic reticuloperitonitis in cattle of Khorramabad (Center of Lorestan Provenience, West of Iran). Global Veterinaria. 5(2): 135-139.

Ibrahim, H.M. and Gomma, N.A. (2016). Traumatic pericarditis in cattle: Risk factors, clinical features and ultrasonographic findings. Journal of Veterinary Science and Medical Diagnosis. 5: 3 .
Mohamed, M.G. (2010). A comparative study on traumatic reticuloperitonitis and traumatic pericarditis in Egyptian cattle. Turkish Journal of Veterinary and Animal Science. 34(2): 143-153.

Radostits, O.M., Gay, C.C., Inchcli, K.W., Constable, P.D. (2007). Veterinary medicine. A textbook of diseases of cattle, horses, sheep, pigs and goats (10 ${ }^{\text {th }}$ edition). Saunders and Elsevier, USA: 471-530.

Rajput, P.K., Parikh, P.V., Parmar, J.J., Mehta, T.A., Patil, D.B. (2018). Studies on foreign body syndrome in bovines of Anand district of Gujarat. Indian Journal of Animal Research. 52(5): 744-749.

Reddy, B.S., Reddy, B.S.S., Sivajothi, S., Reddy, B.S. (2014). Traumatic reticuloperitonitis in cattle: A clinical study. International Journal of Scientific World. 2(1): 13-15.

Roth, L. and King, J.M. (1991). Traumatic reticulitis in cattle: a review of 60 fatal cases. Journal of Veterinary Diagnostic Investigation. 3: 52-54.

Saleh, M.A., Rateb, H.Z., Misk, N.A. (2008). Comparison of blood serum proteins in water buffaloes with traumatic reticuloperitonitis and sequelae. Research in Veterinary Science. 208-213.

Sasikala, K., Vijaykumar, G., Sivaraman, S., Balasubramanian, G. (2018). Clinico Diagnostic Studies on Traumatic Cases. International Journal of Current Microbiology and Applied Science. 7(5): 513-523.

Suthar, A.N., Sutariya, P.T., Patel, J.B., Jadhav, K.M., Prajapati, A.S. (2017). Clinical, ferroscopic and ultrasonographic investigation in diaphragmatic hernia and traumatic pericarditis in buffaloes. Intas Polivet. 18(2): 516-520. 